\title{
INFLUENCE OF GESTATIONAL EXPOSURE ON THE EFFECTS OF PRENATAL EXPOSURE TO METHYL MERCURY ON POSTNATAL DEVELOPMENT IN RATS
}

\author{
Dinesh N. Gandhi , Govind M. Panchal , Dinesh K. Dhull \\ Department of Neurobehavioural Toxicology, National Institute of Occupational Health (ICMR), Meghaninagar, Ahmedabad, Gujarat, India
}

\begin{abstract}
SUMMARY
Fish and other aquatic organisms are important source of dietary proteins for the human population. Fish meat, however, is contaminated with methyl mercury (MeHg), a potent neurotoxin. The well known Minamata and Niigata epidemic outcomes in Japan have raised the awareness of the health risk resulting from consumption of fish (and shellfish) from water basins polluted with industrial wastes containing mercury. In the present study, pregnant rat dams were exposed to environmental toxic elements - methyl mercury, 1000-1200 h, daily from the fifth gestation day (GD5) till parturition. Three groups of animals were given, by gavages, $\mathrm{MeHg}(0.5,1.0$ and $2.0 \mathrm{mg} / \mathrm{kg} / \mathrm{day})$ and control group received $0.9 \%$ saline at the same time. All animals were allowed to deliver and wean their offspring. Pups were evaluated for early development effects. There was a significant effect of treatment on somatic growth such as reduction in percentage of maternal weight gain $(20.62 \%)$ at higher dose level whereas there was no change in percentage of live birth (100.00\%) with 0.5 and $1.0 \mathrm{mg} / \mathrm{kg}$ dose treatment groups. There was a significant increase in the percentage of resorption (100.00\%) per litter with $2.0 \mathrm{mg} / \mathrm{kg} /$ day MeHg dose. Average gestation length (days) and percentage resorption per litter or percentage foetuses/malformations per litter were not affected at 0.5 and $1.0 \mathrm{mg} / \mathrm{kg} /$ day dose level. The results of the study confirmed the high-teratogenic potential of MeHg and the need of payng increased attention to MeHg concerning its exogenous use during pregnancy.
\end{abstract}

Key words: methyl mercury, prenatal exposure, postnatal development, maternal toxicity, fetotoxicity, rats

Address for correspondence: D. N. Gandhi, Department of Neurobehavioural Toxicology, National Institute of Occupational Health (ICMR), Meghaninagar, Ahmedabad 380 016, Gujarat, India. E-mail: d_gandhi28@yahoo.co.in

\section{INTRODUCTION}

Methyl mercury $(\mathrm{MeHg})$, an organic methylated form of mercury, exists in aquatics receiving industrial wastes containing mercury. The health impact of water contamination with $\mathrm{MeHg}$ continues to draw concern of researchers since accidental poisoning that occurred in Minamata and Niigata, Japan and in $\operatorname{Iraq}(1,2)$. The accumulation of $\mathrm{MeHg}$ in fish tissue (10-40 ppm) and subsequent consumption of this contaminated fish tissue by humans pose the greatest health risk. Faroe Islands cohort study reported MeHg-induced deficits in some neurological and cognitive functions in school-age children (3). The principal sources of exposure to mercury in the general population are ingestion and inhalation of mercury compounds from dental amalgams, and ingestion of fish (fresh water and marine) and seafood, which contain mercury, primarily as methyl mercury. Due to its ubiquitous presence in the environment health concerns are increasing. The epidemiological and animal studies demonstrate that the foetuses are more vulnerable to $\mathrm{MeHg}$ neurotoxicity than mothers, as the sensitivity of the nervous system to $\mathrm{MeHg}$ toxicity is the highest during developmental stages $(4,5)$. The major target site of $\mathrm{MeHg}$ intoxication is the nervous system. Specifically it concerns brain functions involved in sensory and coordination skills.

In order to better understand the potential risk of $\mathrm{MeHg}$ exposure and to provide necessary control, an extensive experimental study on the effect of prenatal, postnatal and perinatal $\mathrm{MeHg}$ exposures were conducted in the last few decades $(4,6-8)$. How- ever, the detailed mechanisms of MeHg-induced developmental neurotoxicity are still not fully understood. Exposure to metalinduced developmental toxicity in mammals during gestation and lactation potentially cause adverse effects on foetuses and neonates (9). Similarly, epileptogenic effect was reported after chronic exposure of intrauterine organic and inorganic mercury in developing rat (10). Thus, it is likely that maternal fish intakerelated $\mathrm{MeHg}$ exposure during pregnancy at levels safe for mothers may affect adversely the developing nervous system of foetus. This possibility is supported by data from studies of the victims of the mass MeHg poisonings in Japan $(1,2,11)$.

Although, no evidence of maternal and embryo/foetal toxicity when high doses of $\mathrm{MeHg}$ were given by gavages during GD5 till parturition to pregnant rats; signs of maternal and developmental toxicity in rat were observed when $\mathrm{MeHg}$ was given concurrently. So it further worsened $\mathrm{MeHg}$ toxicity even before birth, adding up the impact throughout life. However, the impact depends on exposure, duration of exposure, route of exposure as well as form of exposure. As a result, the number of populations that are at risk of $\mathrm{MeHg}$ toxicity is not known and should be determined. It is essential to establish an ideal study design, which more closely resembles that of humans. However, till date, no such study design has been established that would help to fill these lacunas. Therefore, the objective of the present study is three-fold: (a) to establish the experimental design that can better represent possible human exposure, (b) to investigate at which developmental stage $\mathrm{MeHg}$ cause neurotoxicity to the rat's foetuses, and (c) 
to assess whether in utero/gestational $\mathrm{MeHg}$ exposure, a wellknown teratogen, has a detrimental impact on early physical and neurodevelopment outcomes.

\section{MATERIALS AND METHODS}

\begin{abstract}
Animals
Mature male and female rats weighing 180-200 g were obtained from the National Institute of Occupational Health (NIOH) breeding colony. After one-week acclimation in the laboratory, female rats were mated with males $(2: 1)$ overnight and examined the following morning for vaginal smears. Vaginal smears were taken daily between 9 and 10 a.m. from mated females. On the day when spermatozoa in the vaginal smear were found, the female was weighted and this day was regarded as the first day of gestation (GD0). During the experimental period, rats were placed in an animal room (temperature $22 \pm 2^{\circ} \mathrm{C}$, relative humidity of $65 \pm 5 \%$, and $12 \mathrm{~h}$ light/dark cycle), with free access to food (Purina lab chow) and tap water. The study was approved by the Institutional Animal Ethics Committee (IAEC) and the experiments were performed in accordance with the Guidelines of the Committee for the Purpose of Control and Supervision of Experimental Animals (CPCSEA), India.
\end{abstract}

\section{Chemical}

Exposure to methyl mercury ( $\mathrm{MeHg}$ ) was given by oral gavages and it was purchased from Sigma Aldrich, USA.

\section{Exposure and Exposure Control Groups}

In experimental groups, the exposure was carried out from the day 5 of gestation until the parturition by gavages on Wister albino rats and the maternal cohort in experiment (exposure to $\mathrm{MeHg}$ ) consisted of 29 pregnant females separated into four groups: $0.5 \mathrm{mg} / \mathrm{kg} / \mathrm{day}$ $\mathrm{MeHg}$ group (n=8);1.0 mg/kg/day MeHg group (n=7); $2.0 \mathrm{mg} / \mathrm{kg} /$ day $\mathrm{MeHg}$ group $(\mathrm{n}=7)$, and a control group $(\mathrm{n}=7)$ received $0.9 \%$ saline at the same time as MeHg. The level of dose was based on data showing that at this exposure level, the mercury concentration in newborn rats was comparable to that one found in human infants born in populations with high dietary fish consumption $(11,12)$.

\section{Observation Made During Pregnancy}

Beginning on GD21, dams were inspected frequently between 8 a.m. and 8 p.m. for birth until delivery. Each presumably pregnant female was checked twice a day for completion of or difficulties in parturition. The day of parturition was defined as postnatal day (PND0), meaning the maximum resolution for gestational length was one half day. The pups were counted, examined for gross malformation and weighed individually. Pups body weight and maternal behaviour was recorded daily during nursing. After parturition, the neonates were observed for mortality and signs of toxicity.

\section{Assessment of the Reproduction Success}

Survival, growth, development, and behaviour of the offspring were evaluated. When parturition was completed, the number of stillborn, implantation, postimplantation, resorption, and live pups in each litter were recorded. Following variables were observed. Birth measures: offspring were examined on PND1 for obvious morphological anomalies (e.g., missing digits, facial malformations etc.), sexed by relative anogenital distance and culled pseudo-randomly to twenty animals of either sex.

\section{Assessment of the Offspring's Morphological Devel- opment}

Gestation length was calculated at birth and the following offspring data were collected on PND1: pups size, sex ratio (as percent males), body weight for each pup, and the number of malformed offspring. Neonatal death was noted from PND1 through PND5. Offspring remained with their biological mother and postnatal biobehavioural maturation of the pups was assessed over the first 3 postnatal weeks, until they were weaned on PND23.

\section{Assessment of the Offspring's Physical Development}

On PND1, the pups were identified within each group of treatment and were assessed. Pups from each litter were weighed on PND1, 7, 14, and 21, and the emergence of physical maturation landmarks were noted each day, including pinna detachment (PND2-5); incisor irruption (PND6-7); eye opening (PND1116); development of fur (PND9); ear unfolding (PND2) (13); tastes descendent (PND25) (14), and vaginal opening (PND30) (14) at the appropriate ages. All pups in each litter were assessed every day scheduled even after attaining each milestone.

\section{Maternal Behaviour}

Maternal behaviour was observed daily in the home cage of each dam and her litter between gestational day 21 and postdelivery day (PND) 1 till 14. The time of observation was during the light phase of light/dark cycle, between 8 a.m. and 9 p.m. The following behaviours were recorded: number of pups nourished; number of pups not nourished; number of pups with mother; number of pups alone, and number of pups with others.

\section{Statistical Analysis}

Data were analysed by one-way analysis of variance (ANOVA) followed by Duncan test. The level of statistical significance was set at $\mathrm{p}<0.05$. All data are expressed as means \pm S.E.M.

\section{RESULTS}

\section{Effects of Exposure to Methyl mercury \\ Maternal Health Status and Reproduction Outcome}

The distribution and fate of all mated rats are given in Table 1. During pregnancy the treatment groups did not differ in water and food intake (data not shown), and in the rate of body mass increase. Pregnant rats neither produced any noticeable signs of toxicity nor symptoms related to $\mathrm{MeHg}$ doses administered by gavages during treatment period. Behaviour of the treated rats was 
almost similar to that of the control rats. On day 4 of gestation, the maternal body weight remained within the control range. The respective control values $(\mathrm{g})$ were $228.75 \pm 18.10 ; 227.02 \pm 6.70$; 217.26 \pm 7.98 ; and $213.97 \pm 9.95$. On day 20 of gestation, the maternal body weight gain $(\mathrm{g})$ of control and three dose levels $(0.5$, 1.0 and $2.0 \mathrm{mg} / \mathrm{kg}$ /day) $\mathrm{MeHg}$ exposed dams were $101.00 \pm 3.59$; $107.42 \pm 2.22 ; 103.93 \pm 0.95$; and $44.11 \pm 4.88$. Maternal weight gain of dams during gestation and percentage weight gain during treatment was significantly reduced in the high dose $(2.0 \mathrm{mg} / \mathrm{kg} /$ day) $\mathrm{MeHg}$ treatment group along with observed anxiety and hindlimb ataxia (Table 1).

\section{Maternal Toxicity}

There were no clinical signs attributed to all $\mathrm{MeHg}$ expose dose levels observed during the treatment period. Commencing on GD5 till parturition, the high dose level $\mathrm{MeHg}$ group of animals developed gait alterations and incoordination. The animals later became difficult to handle and showed limb abnormalities including exaggerated movements, and limited usage of the hind limbs. As a result of the poor condition of these animals, these were euthenized early in lactation (LD 0 or 1 ) due to dystocia, delivery of dead pups, or total litter loss. Gross pathological examination of animals to litter or complete parturition indicated undelivered dead foetuses or resorptions in the uterus. On occasion, dark material was found in the vagina. All other animals in the low dose $(0.5$ and $1.0 \mathrm{mg} / \mathrm{kg} /$ day $) \mathrm{MeHg}$ groups appeared normal, there were no adverse clinical signs along with deaths, resorbed or late deliveries observed. However, hundred percent of resorbed pups as well as significant reduction in body weight gain during gestation were observed in the high dose $\mathrm{MeHg}$ treatment group (Table 1, 2).

\section{Embryo/Foetal Toxicity}

Summary of the foetal toxicity findings is presented in Table 3 . There were no significant differences among groups in the number of total implants per litter or in the sex ratio. The numbers of total resorptions and dead foetuses as well as the percentage of post implantation loss were only significantly affected by treatment with high dose of $\mathrm{MeHg}$. The average total body weight on PND1 per litter was also significantly decreased with low doses of MeHg-treatment groups. The number of pups delivered varied from 9 to 10 in both control and $\mathrm{MeHg}$-treated dams. No significant differences in MeHg-treated offspring's body weight were detected compared to control at birth as well as on PND14 and PND21 (Table 2). There were no significant differences in the number of pups per litter, male/female ratio, or the number of stillbirths with low dose levels of $\mathrm{MeHg}$ treatment groups. However, values of the viability index (i.e. percentage of pups surviving beyond PND4) were notably lower in the high dose $\mathrm{MeHg}$-treated group as compared to the control group (Table 3 ).

\section{Effects of Maternal MeHg Exposure in the Offspring Body Weight}

There were no differences between the progeny of the control and $\mathrm{MeHg}$ exposed groups in body weight at PND1 individually. In successive days, however, in pups of the low doses of MeHgtreatment groups, in either sex, body weight non-significantly increases on PND1, PND14, PND21, pups were smaller than in the control group, whereas hundred percentage of resorption of the pups were observed in the high dose $\mathrm{MeHg}$ treatment group (Table 2).

Table 1. Maternal and litter characteristics (mean \pm S.E.M) ${ }^{a}$

\begin{tabular}{|l|c|c|c|c|}
\hline Dose of MeHg & Control & $0.5 \mathrm{mg} / \mathrm{kg}$ & $1.0 \mathrm{mg} / \mathrm{kg}$ & $2.0 \mathrm{mg} / \mathrm{kg}^{\boldsymbol{s}}$ \\
\hline Dams (N=29) & 7 & 8 & 7 & 7 \\
\hline Maternal weight on GD0 (g) & $228.75 \pm 18.10$ & $227.02 \pm 6.70$ & $217.26 \pm 7.98$ & $213.97 \pm 9.95$ \\
\hline Maternal weight gain to GD20 (g) & $101.00 \pm 3.59$ & $107.42 \pm 2.22$ & $103.93 \pm 0.95$ & $44.11 \pm 4.88$ \\
\hline Maternal weight gain (\%) & 44.15 & 47.32 & 47.84 & $20.62^{* *}$ \\
\hline Total no. of pups born (N=219) & 66 & 80 & 73 & - \\
\hline Live births (\%) & 100.00 & 100.00 & 100.00 & $0.00^{* *}$ \\
\hline No. of pups alive & 66 & 79 & 73 & - \\
\hline No. of pups dead & 0 & 1 & 1 & - \\
\hline Viability (\%) & 100.00 & 98.73 & 98.63 & - \\
\hline Gestational age (days) & $21.00 \pm 0.00$ & $21.00 \pm 0.00$ & $21.14 \pm 0.12^{*}$ & $28.00 \pm 0.00^{* * *}$ \\
\hline Litter size & & & & \\
\hline Males & $4.71 \pm 2.98$ & $5.25 \pm 2.87$ & $5.14 \pm 1.95$ & - \\
\hline Females & $4.71 \pm 1.98$ & $4.63 \pm 2.39$ & $5.29 \pm 2.29$ & - \\
\hline Sex ratio (M/M+F) & 0.49 & 0.54 & 0.49 & - \\
\hline Dead pups on PND1 to PND5 & 0 & 0 & 0 & - \\
\hline Mean weight on PND1 (g) & $44.96 \pm 0.56(66)$ & $39.11 \pm 1.34^{*}(79)$ & $38.50 \pm 2.47^{*}(73)$ & - \\
\hline
\end{tabular}

aMean \pm S.E.M. maternal litter characteristics of 29 confirmed pregnant dams and their pups delivered.

bOf the total of 29 dams received in the experiment.

cTotal number of pups delivered from respective dams of each group of treatment. ${ }^{*} p<0.05,{ }^{* *} p<0.01,{ }^{* * *} p<0.001$ compared to control

${ }^{\$}$ Resorption of all pups. Dams were not delivered till GD28. 
Table 2. Effects of Methyl mercury $(\mathrm{MeHg})$ on gestational parameters in pregnant rats

\begin{tabular}{|c|c|c|c|c|}
\hline & Control & $0.5 \mathrm{mg} / \mathrm{kg} \mathrm{MeHg}$ & $1.0 \mathrm{mg} / \mathrm{kg} \mathrm{MeHg}$ & $2.0 \mathrm{mg} / \mathrm{kg} \mathrm{MeHg}$ \\
\hline No. of dams & 7 & 8 & 7 & 7 \\
\hline Implants/Litter & $9.86 \pm 2.54$ & $10.00 \pm 2.33$ & $10.43 \pm 0.79$ & $9.29 \pm 0.86$ \\
\hline Live foetuses/Litter & $9.43 \pm 2.15$ & $9.88 \pm 2.30$ & $10.43 \pm 0.79$ & 0.00 \\
\hline Dead foetuses/Litter & $0.13 \pm 0.79$ & $0.13 \pm 0.35$ & $0.14 \pm 0.38$ & $9.29 \pm 0.86^{* *}$ \\
\hline Total resorbed/Litter (\%) & 0.00 & 0.00 & 0.00 & $100.00^{* *}$ \\
\hline Total resorption and dead fetuses/Litter (\%) & 0.00 & 0.00 & 0.00 & $100.00^{* *}$ \\
\hline Postimplantation loss (\%) & 1.32 & 1.30 & 1.34 & $100.00^{* *}$ \\
\hline Total male pups/Dam & $4.71 \pm 2.98(33)$ & $5.25 \pm 2.87(42)$ & $5.14 \pm 1.95(36)$ & 0.00 \\
\hline Total females/Dam & $4.71 \pm 1.98(33)$ & $4.63 \pm 2.39(37)$ & $5.29 \pm 2.29(36)$ & 0.00 \\
\hline Sex ratio $(M / M+F)$ & 0.49 & 0.54 & 0.49 & 0.00 \\
\hline Males foetal body weight (g) (PND1) & $6.16 \pm 0.42$ & $6.14 \pm 0.35$ & $6.06 \pm 0.30$ & 0.00 \\
\hline PND14 & $17.92 \pm 1.09$ & $17.47 \pm 1.15$ & $19.10 \pm 1.67$ & 0.00 \\
\hline PND21 & $24.38 \pm 0.82$ & $24.06 \pm 1.11$ & $26.43 \pm 3.09$ & 0.00 \\
\hline Females foetal body weight (g) (PND1) & $5.67 \pm 1.06$ & $5.88 \pm 0.41$ & $5.81 \pm 0.42$ & 0.00 \\
\hline PND14 & $17.47 \pm 0.88$ & $17.56 \pm 1.46$ & $18.50 \pm 2.12$ & 0.00 \\
\hline PND21 & $24.04 \pm 0.78$ & $24.65 \pm 1.21$ & $25.45 \pm 2.38$ & 0.00 \\
\hline Males body length (mm) & $68.17 \pm 1.24$ & $69.00 \pm 1.23$ & $66.58 \pm 1.71$ & 0.00 \\
\hline Females body length (mm) & $67.97 \pm 1.23$ & $68.54 \pm 1.10$ & $66.25 \pm 2.25$ & 0.00 \\
\hline Males tail length (mm) & $18.09 \pm 0.69$ & $18.83 \pm 0.75$ & $17.22 \pm 1.27$ & 0.00 \\
\hline Females tail length (mm) & $18.53 \pm 0.87$ & $18.92 \pm 0.68$ & $17.53 \pm 1.11$ & 0.00 \\
\hline
\end{tabular}

Data are presented as mean \pm S.E.M. Significantly different from the control group: ${ }^{*} p<0.05$, ${ }^{* *} p<0.01,{ }^{* * *} p<0.001$, respectively.

Table 3. Effect of Methyl mercury on pup's mortality

\begin{tabular}{|c|c|c|c|c|}
\hline \multirow{2}{*}{ Treatment groups } & \multirow{2}{*}{ Litter size } & \multirow{2}{*}{ Gender ratio (M/M+F) } & \multicolumn{2}{|c|}{ Pup mortality } \\
\hline & & & PND1-4 & Litters affected \\
\hline Control & $9.43 \pm 2.15$ & 0.49 & $4.36 \%$ & $2 / 7$ \\
\hline $0.5 \mathrm{mg} / \mathrm{kg} \mathrm{MeHg}$ & $9.88 \pm 2.30$ & 0.54 & $1.30 \%$ & $1 / 8$ \\
\hline $1.0 \mathrm{mg} / \mathrm{kg} \mathrm{MeHg}$ & $10.43 \pm 0.79$ & 0.49 & $1.32 \%$ & $1 / 7$ \\
\hline $2.0 \mathrm{mg} / \mathrm{Kg} \mathrm{MeHg}$ & $0.00^{* \star}$ & 0.00 & $0.00^{* *}$ & $7 / 7^{* \star *}$ \\
\hline
\end{tabular}

Data are presented as mean \pm S.E.M. Significantly different from the control group: ${ }^{*} p<0.05,{ }^{* *} p<0.01,{ }^{* * *} p<0.001$, respectively.

\section{Assessment of the Reproduction Success}

Reproduction success by measuring different gestational parameters were not significantly affected in the low dose levels of $\mathrm{MeHg}$ exposed groups during gestation, indicating that both low dose $\mathrm{MeHg}$ exposed groups had no adverse developmental effect on the progeny as well as timing of developmental milestones; whereas reproduction success in the high dose of $\mathrm{MeHg}$ treatment group resulted in a hundred percentage of resorption of the pups (Table 2).

\section{Assessment of the Offspring's Morphological Development}

The length of gestation was not statistically different between the control and $\mathrm{MeHg}$-treated groups, however, there was an indication of an extended length for dams exposed to 1.0 and 2.0 $\mathrm{mg} / \mathrm{kg} /$ day. Prenatal administration of low dose of $\mathrm{MeHg}$ treatment groups resulted into no change in percentage of live births during the first day of postnatal life as well as on viability. How- ever, percentages of pups' viability at birth as well as resorption per litter were significantly affected in the high dose of $\mathrm{MeHg}$ exposed group. As a result, there was a significant effect of $\mathrm{MeHg}$ on increase in post-implantation loss. No statistical differences were noted for the low dose MeHg-treated groups, as indicated by the general appearance, stillbirths, the number of pups per litter pups weight, mean pup weight, litter size, sex ratio, the viability index, and mortality (Table 2, 3).

\section{Assessment of the Offspring's Physical Development}

Pups of all exposed groups, male and females, did not differ statistically from their counterparts in the onset of development for pinna detachment (unfolding), incisor eruption, eye opening, testes descent, and vaginal opening between the control and low dose $\mathrm{MeHg}$-treated groups. However, these tests were not observed with the high dose MeHg-treated group due to hundred percent resorption of pups. 


\section{DISCUSSION}

Dental amalgams containing 50\% mercury $(\mathrm{Hg})$ have been used in dentistry for the last 150 years, and $\mathrm{Hg}$ exposure during key developmental periods was associated with autism spectrum disorders (ASDs). As a result, dental amalgams are a significant source of mercury body burden, as studies in animals (16) and humans show $(17,18)$. Also, mercury from maternal amalgam fillings leads to a significant increase of mercury concentration in the tissues and hair of foetuses and newborn children (17) as well as of dentists, workers in fish industry, and professionally non-exposed adults (19).

In recent years, some attention has been given to consequences of exposure to $\mathrm{MeHg}$ during pregnancy and the early postnatal period. Although some attention has been paid to such effects on the foetus development, full evaluation of risk effects has not been undertaken. This is of particular concern as exposure of the developing nervous system to $\mathrm{MeHg}$ toxic effects may have very different consequences than those resulting from exposure of the adult nervous system. Furthermore, a developing foetus is more susceptible to and affected by lower doses than those required to produce changes in the adult central nervous system (20). Few animal studies have examined potential adverse effects of $\mathrm{MeHg}$ on the developing offspring taking into account the human exposure scenario of chronic ingestion of $\mathrm{MeHg}$ through the consumption of contaminated fish. Many of the animal studies, especially the earlier ones (6-8), administered $\mathrm{MeHg}$ for only a brief period during gestation. In addition, the endpoints evaluated were often limited in scope. The selection of dose levels, manner of administration, and duration of exposure will no doubt directly impact the outcomes being measured.

It is well established that exposure to toxic elements such as mercury or arsenic during gestation and lactation may potentially cause adverse effects on the development of foetuses and neonates $(9,10)$. The foetus is especially susceptible to $\mathrm{MeHg}$-induced embryo/foetal toxicity found in animals exposed during gestation (4). Earlier studies reported MeHg-induced embryo/foetal toxicity (including teratogenesis) in mice and rats $(9,21-23)$. Although in the current study no maternal lethality was observed in any exposed group, there were also no significant differences in the number of live foetuses per litter, the number of nonviable implants per litter, or the percentage postimplantation loss between the control group and the groups receiving $\mathrm{MeHg} 0.5$ and $1.0 \mathrm{mg} / \mathrm{kg} / \mathrm{day}$. In contrast, a high incidence of prenatal mortality was recorded in the group exposed to $2.0 \mathrm{mg} / \mathrm{kg} / \mathrm{day} \mathrm{MeHg}$, significantly increasing the percentage of postimplantation loss up to $100 \%$. According to the above results, gestational exposure (GD5 till parturition) to $\mathrm{MeHg}$ neither enhances nor depresses the $\mathrm{MeHg}$-induced maternal toxicity and embryotoxicity at doses 0.5 and $1.0 \mathrm{mg} / \mathrm{kg}$ / day. In contrast, there were no live foetuses in the group treated with $2.0 \mathrm{mg} / \mathrm{kg} /$ day $\mathrm{MeHg}$; the effect of gestational exposure on $\mathrm{MeHg}$-induced teratogenesis could thus be established.

One of the most common abnormal findings observed in the rats was ataxia, which corresponds well with signs observed in severe human cases of $\mathrm{MeHg}$ poisoning (24). In the present study, the pregnancy length of animals was remarkably increased with the highest dose of $\mathrm{MeHg}$. The reason might be that we had more precise measurements of the data (indicated by smaller standard error), because we recorded this duration by a unit of 0.5 day.
There was a trend toward reduced embryonic implantations in the uterus and the number of dams bearing live pups was markedly diminished. Failure to deliver or sustain live pups illustrated the extreme toxicity of this dose; a reasonable interpretation of which may be that the exposure in the present study was started after implantation of embryo. Similar findings reported by Voorhees (6) treated rats with $\mathrm{MeHg}$ by gavages at $6.0 \mathrm{mg} / \mathrm{kg} /$ day from GD6 to 9 and showed a comparable extension of gestation length. Pregnant mothers exposed to $\mathrm{MeHg}$ high doses from contaminated fish in Japan reported miscarriages, or had children stillborn, or dying shortly after birth (25). Dietary exposure via drinking water during gestation and lactation at doses of 0.5 and $2.0 \mathrm{mg} / \mathrm{kg} /$ day was used in some studies $(25,26)$. Some of the data could be compared with those studies, rats received $\mathrm{MeHg}$ at two dosing levels: 2.0 or $6.0 \mathrm{mg} / \mathrm{kg}$ b.w. from GD6 to GD9 (8) as well as 0.5 and $2.0 \mathrm{mg} / \mathrm{kg}$ b.w. from day 7 of pregnancy (GD7) up to day 21 (PND21) after the delivery and $\mathrm{MeHg}$ in drinking water (27). The number of pups per litter, gender proportion in litters and pup viability were not affected by 0.5 or $1.0 \mathrm{mg} / \mathrm{kg} / \mathrm{day} \mathrm{MeHg}$ exposure; whereas the offspring mortality or resorption in $2.0 \mathrm{mg} /$ $\mathrm{kg}$ /day $\mathrm{MeHg}$ exposure group was significantly increased up to hundred percent. In the present study, the effect on the offspring's morphological development in the progeny of each exposed group was retarded growth possibly due to poor health of the mothers.

Postnatal effects of $\mathrm{MeHg}$ exposure have been well documented. Hughes and Annau (28) have reported decreased litter size in mice given $\mathrm{MeHg} 3$ to $10 \mathrm{mg} / \mathrm{kg} /$ day on GD8. Effects on reproduction studied in non-human primates have shown diminished conception rates and increased incidences of abortions and stillbirths in Macaques treated for 4 months with $70 \mathrm{mg} /$ $\mathrm{kg}$ /day (29). In the present study, pups of the exposed groups, MeHg-treated ( 0.5 and $1.0 \mathrm{mg} / \mathrm{kg} /$ day $)$, male and females, did not differ statistically from their control counterparts in the onset of development for pinna detachment (unfolding), incisor eruption, eye opening, testes descent, and vaginal opening. However, these tests were not observed with the $2.0 \mathrm{mg} / \mathrm{kg} /$ day $\mathrm{MeHg}$-treated group due to hundred-percentage resorption of pups. There was no adverse effect on postnatal survival of the pups. The body weights of the pups were unaffected at birth and continued to be unaffected throughout the pre-weaning period with 0.5 and 1.0 $\mathrm{mg} / \mathrm{kg} /$ day $\mathrm{MeHg}$-treated groups. Harada (25) reported that the physical growth of Japanese children exposed to MeHg in-utero was altered. Most developmental landmarks were unaffected by $\mathrm{MeHg}$ in the current study, however, the maternal exposure to $\mathrm{MeHg}$ resulted in the pups eyes opening earlier (30). Other physical developmental test changes in rats reported elsewhere has included an earlier development for incisor eruption $(8,29)$, delayed testicular descent, and vaginal opening $(8,30,31)$.

Alteration in behaviour of the mother is known to affect infant development and several drugs have been shown to disrupt elements of maternal behaviour (32). Thus, any disturbance to maternal care or the delicate mother-pup relationship may explain different patterns of behaviour in the offspring rather than direct effects of prenatal exposure to a toxicant. The results of the present study suggested that control mothers (dam) spent more time involved in the pup-directed behaviour of nursing and licking and less time in nest-building during the first two postnatal weeks than dams treated with methyl mercury during gestation. Once delivered the pups, control as well as dams treated with 
methyl mercury involved in nursing and licking behaviour rather than in nest building.

In conclusion, an important principle of teratology is that the harm caused by a toxic agent is concurrence of several factors, including the individual's genetic makeup, the foetal and postnatal environment, the dose of the agent, and the developmental stage of the foetus at the time of exposure. Several population studies looking at effects of prenatal exposure to $\mathrm{MeHg}$ show a large variation in outcomes of neurological endpoints. These results suggest that tolerance and susceptibility to $\mathrm{MeHg}$ toxicity vary widely among individuals within a population and, furthermore, indicate the potential existence of mechanisms that protect individuals from $\mathrm{MeHg}$. The results of the present study confirmed that the prenatal administration of methyl mercury at highest dose produced adverse effects on developmental milestones and high-teratogenic potential of $\mathrm{MeHg}$ and suggest to pay increased attention to $\mathrm{MeHg}$ concerning its exogenous use during pregnancy. Pregnancy is a unique time when a woman may seek treatment out of concern for health and well being of her child. Substance use during pregnancy can affect the developing foetus both directly, through passage of the toxicant through the placenta, and indirectly, through poor maternal health habits and environmental conditions. Finally, developmental outcomes may be optimized by interventions that occur early in life, are tailored for environmental pollutants, addictive substances, drugs, malnutrition, excessive stress, and/or hypoxia-ischemia induced maldevelopment of the brain with consequent neurobehavioural disorders. The appropriate model animals and study design might provide valuable tools in the search for a refined biological marker for detecting a possible severe cognitive dysfunction in adults or the elderly of an exposed human population.

\section{Acknowledgement}

The authors acknowledge the Indian Council of Medical Research (ICMR), New Delhi, India for funding the ad-hoc Research Project No.2010-04390 and awarding Senior Research Fellow (SRF) to the author (DKD) under this project.

\section{Conflict of Interests}

None declared

\section{REFERENCES}

1. Takeuchi T. Human effects of methylmercury as an environmental neurotoxicant. In: Blum K, Manzo L, editors. Neurotoxicology. New York: Marcel Dekker; 1985. p.345-67.

2. Amin-Zaki L, Elhassani S, Majeed MA, Clarkson TW, Doherty RA, Greenwood M. Intra-uterine methylmercury poisoning in Iraq. Pediatrics. 1974 Nov;54(5):587-95.

3. Grandjean P, Weihe P, White RF, Debes F, Araki S, Yokoyama K, et al. Cognitive deficit in 7-year-old children with prenatal exposure to methylmercury. Neurotoxicol Teratol. 1997 Nov-Dec;19(6):417-28.

4. Eccles CU, Annau Z. Prenatal methyl mercury exposure: I. Alterations in neonatal activity. Neurobehav Toxicol Teratol. 1982 May-Jun;4(3):371-6.

5. Grandjean P, Landrigan PJ. Developmental neurotoxicity of industrial chemicals. Lancet. 2006 Dec 16;368(9553):2167-78.

6. Vorhees CV. Behavioral effects of prenatal methylmercury in rats: a parallel trial to the Collaborative Behavioral Teratology Study. Neurobehav Toxicol Teratol. 1985 Nov-Dec;7(6):717-25.

7. Fredriksson A, Gårdlund AT, Bergman K, Oskarsson A, Ohlin B, Danielsson B, et al. Effects of maternal dietary supplementation with selenite on the postnatal development of rat offspring exposed to methyl mercury in utero. Pharmacol Toxicol. 1993 Jun;72(6):377-82.
8. Sitarek K, Gralewicz S. Early developmental effects of separate or combined perinatal exposure to methylmercury $(\mathrm{MeHg})$ and 2,2', 4,4',5, 5'-hexachlorobiphenyl (PCB 153) in the rat. Int J Occup Med Environ Health. 2009;22(2):89-105.

9. Domingo JL. Metal-induced developmental toxicity in mammals: a review. J Toxicol Environ Health. 1994 Jun;42(2):123-41.

10. Barna B, Szász A, Gajda Z, Galbács Z, Kirsch-Volders M, Szente M. Effects of chronic, intrauterine organic and inorganic mercury intoxication on the epileptogenicity of developing rat. Cent Eur J Public Health. 2000 Jul;8 Suppl:73-5.

11. Amin-Zaki L, Majeed MA, Elhassani SB, Clarkson TW, Greenwood MR, Doherty RA. Prenatal methylmercury poisoning. Clinical observations over five years. Am J Dis Child. 1979 Feb;133(2):172-7.

12. Rossi AD, Ahlbom E, Ogren SO, Nicotera P, Ceccatelli S. Prenatal exposure to methylmercury alters locomotor activity of male but not female rats. Exp Brain Res. 1997 Dec;117(3):428-36.

13. Cernichiari E, Brewer R, Myers GJ, Marsh DO, Lapham LW, Cox C, et al. Monitoring methylmercury during pregnancy: maternal hair predicts fetal brain exposure. Neurotoxicology. 1995 Winter;16(4):705-10.

14. Lapointe G, Nosal G. A rat model of neurobehavioral development. Experientia. 1979 Feb 15;35(2):205-7.

15. Kandel, E.R. Cellular basis of behaviour: an introduction to behavioral neurobiology. San Francisco: W. H. Freeman; 1976.

16. Olczyk K, Kucharz EJ, Głowacki A. Influence of chronic mercury poisoning upon the connective tissue in rats. I. Effect of mercuric chloride on glycosaminoglycan levels in tissues, serum and urine. Cent Eur J Public Health. 1994 Dec;2(2):77-9.

17. Mutter J, Naumann J, Guethlin C. Comments on the article "The toxicology of mercury and its chemical compounds" by Clarkson and Magos (2006). Crit Rev Toxicol. 2007;37(6):537-49.

18. Geier DA, Kern JK, Geier MR. A prospective study of prenatal mercury exposure from maternal dental amalgams and autism severity. Acta Neurobiol Exp (Wars). 2009;69(2):189-97.

19. 19 Wranová K, Čejchanová M, Spěváčková V, Korunová V, Vobecký M, Spěváček V. Mercury and methylmercury in hair of selected groups of Czech population. Cent Eur J Public Health. 2009 Mar;17(1):36-40.

20. Snell K, editor. Developmental toxicology. London: Croom Helm; 1982.

21. Fuyuta M, Fujimoto T, Hirata S. Embryotoxic effects of methylmercuric chloride administered to mice and rats during orangogenesis. Teratology. 1978 Dec;18(3):353-66.

22. Su MQ, Okita GT. Embryocidal and teratogenic effects of methylmercury in mice. Toxicol Appl Pharmacol. 1976 Oct;38(1):207-16.

23. Yasuda Y, Datu AR, Hirata S, Fujimoto T. Characteristics of growth and palatal shelf development in ICR mice after exposure to methylmercury. Teratology. 1985 Oct;32(2):273-86.

24. World Health Organization. Methylmercury. Environmental health criteria 101. Geneva: WHO; 1990.

25. Harada M. Minamata disease: methylmercury poisoning in Japan caused by environmental pollution. Crit Rev Toxicol. 1995;25(1):1-24.

26. Piedrafita B, Erceg S, Cauli O, Felipo V. Developmental exposure to polychlorinated biphenyls or methylmercury, but not to its combination, impairs the glutamate-nitric oxide-cyclic GMP pathway and learning in 3-month-old rats. Neuroscience. 2008 Jul 17;154(4):1408-16.

27. Sitarek K, Gralewicz S. Early developmental effects of separate or combined perinatal exposure to methylmercury (MeHg) and 2, 2', 4, 4', 5, 5'-hexachlorobiphenyl (PCB 153) in the rat. Int J Occup Med Environ Health. 2009;22(2):89-105.

28. Hughes JA, Annau Z. Postnatal behavioral effects in mice after prenatal exposure to methylmercury. Pharmacol Biochem Behav. 1976 Apr;4(4):385-91.

29. Burbacher TM, Mohamed MK, Mottett NK. Methylmercury effects on reproduction and offspring size at birth. Reprod Toxicol. 19871988;1(4):267-78.

30. Buelke-Sam J, Kimmel CA, Adams J, Nelson CJ, Vorhees CV, Wright DC, et al. Collaborative Behavioral Teratology Study: results. Neurobehav Toxicol Teratol. 1985 Nov-Dec;7(6):591-624.

31. Elsner J, Suter KE, Ulbrich B, Schreiner G. Testing strategies in behavioral teratology: IV. Review and general conclusions. Neurobehav Toxicol Teratol. 1986 Sep-Oct;8(5):585-90.

32. Laviola G, Sedowofia K, Innes J, Clayton R, Manning A. Genetic differences in maternal behaviour patterns in mice administered phenobarbital during pregnancy. Psychopharmacology (Berl). 1990;102(3):383-90.

Received March 9, 2012 Accepted in revised form October 23, 2012 